УДК 811.112.2+811.162.1]'373.7

DOI 10.31654/2520-6966-2019-12f-95-193-210

\title{
M. Milczarek
}

Germanista, adiunkt w Katedrze Filologii Obcych Akademii Humanistyczno-Ekonomincznej w Łodzi, specjalizacja językoznawstwo

\section{Klassifikationsmöglichkeiten der phraseologischen Wortverbindungen aus kontrastiver Sicht Deutsch-Polnisch}

W wielu systemach językowych funkcjonują połączenia wyrazowe, które ze względu na swoją utrwaloną formę oraz specyficzne znaczenie stosowane są w komunikacji jako gotowe frazy niosące ze sobą dodatkowo określony ładunek emocjonalny. Znajomość frazeologizmów jest ważna zarówno w nauce języka obcego, jak i w pracy tłumacza. Poprawnie użyte mogą wzbogacać wypowiedź $i$ świadczą o wysokim stopniu opanowania języka obcego. Ich niewłaściwe zastosowanie może jednak doprowadzić do nieplanowanego efektu komicznego lub wręcz zakłócać komunikację. W poniższym artykule w oparciu o różnorodne teksty źródłowe zostaną przedstawione kryteria według których definiuje się frazeologizmy w niemieckim i polskim systemie językowym. Następnie zostanie przedstawiona różnorodność takich grup wyrazowych w obu językach.

Słowa klucze: frazeologia, frazeologizmy, utarte zwroty, przysłowia.

\section{Einführung}

Beim Lernen einer Fremdsprachen stößt man früher oder später auf Wortgruppen, deren Übersetzung Schwierigkeiten bereitet, weil aus der Bedeutung ihrer Komponenten die Gesamtbedeutung schwer zu erschließen oder sogar unmöglich ist. Es handelt sich dabei um Phraseologismen. Feste Wortverbindungen der Art bilden den Gegenstand der Phraseologie. Der Begriff "feste Wortverbindungen" umfasst Wortkomplexe, die sich durch bestimmte Merkmale voneinander unterscheiden, z. B. stehende Wortverbindungen (zu Hause, zu Fuß) Gruß- und Abschiedsformeln (Guten Abend, Grüß Gott, Gute Nacht), Zwillingsformeln (auf Schritt und Tritt), Idiome (für die Katz sein ,vergeblich, nutzlos sein'; [7, S. 376], Sentenzen (die Würfel sind gefallen - ,eine Entscheidung wurde getroffen'; [7, S. 820] Sprichwörter (Einmal ist keinmal).

Bereits an den angeführten Beispielen sieht man ein, dass unter dem Begriff ,phraseologisch' eine Vielfalt von unterschiedlichen 
Wortkomplexen zu verstehen ist. Im Nachstehenden werden die einzelnen Gruppen in zwei Sprachsystemen- im Deutschen und im Polnischen dargestellt, um dadurch feststellen zu können, dass dieses sprachliche Phänomen in unterschiedlichen Sprachen viele Ähnlichkeiten aufweist. Da wird auch auf unterschiedliche Kriterien zum Zweck der Zuordnung zu einer bestimmten Gruppe der Phraseologismen hingewiesen.

\section{Phraseologismen}

Der Terminus ,Phraseologismus' findet in dem griechischlateinischen Wort phrasis ,rednerischer Ausdruck' seine Quelle. [10, S. 2] In der deutschen Sprache existiert der Begriff Phrase schon seit dem 17. Jh. Er wurde aus dem Französischen entlehnt und enthielt neben der heute geläufigen auch eine pejorative Bedeutung als "inhaltsleere Redensart", "inhaltsleere Schönrednerei und Neigung dazu". Noch im 20. Jh. war die negative Bedeutung des Begriffs im Gebrauch. [10, S. 2]

Der "Phraseologismus" kommt als Oberbegriff für verschiedene Teilklassen vor. Dieser Begriff, sowie seine Ableitungen (z. B. phraseologisch, Phraseme, Phrasen, wie auch Phraseologie - als die Bezeichnung der gesamten Teildisziplin) geht - wie bereits erwähnt - auf denselben griechischen und spätlateinischen Terminus zurück.

In den meisten gegenwärtigen Nachschlagewerken kann man folgende Definition des "Phraseologismus" finden:

"feste, stehende Redewendung, Redensart, Phrase. Fest zusammengehörende, unzerlegbare Wortverbindung, deren Gesamtbedeutung häufig nicht mehr die Summe der Bedeutungen ihrer Einzelkomponenten darstellt (Menschen guten Willens), sondern eine Umdeutung (Übertragung) erfahren hat (jemandem den Kopf waschen,ihn rügen'), die oft nicht mehr motiviert erscheint, d. h. sie lässt sich nicht mehr aus den Einzelbedeutungen erschließen (...). Phraseologismen drücken einen einheitlichen Begriff aus, werden in der Funktion eines Einzelwortes gebraucht und können daher häufig durch ein solches ersetzt werden (. . .)" [20, S. 201].

Aus der Sicht der kognitiven Sprachwissenschaft wird als Hauptmerkmal der Phraseologismen die Tatsache gehalten, dass sie in der Kommunikation wie einzelne (Gruppen)Lexeme funktionieren. Auch u. a. A. Pajdzińska [17, S. 12] definiert Phraseologismen, indem sie v. a. auf ihre Festigkeit und Nicht-Summativität der Bedeutung aufmerksam macht:

"Są one złożonymi znakami językowymi - nieswobodnymi, reprodukowanymi z pamięci połączeniami wyrazów, z których każdy występuje zwykle również jako samodzielna jednostka leksykalna. Połączenia te cechuje nieregularność semantyczna: nie wystarczy 
znajomość znaczeń komponentów i schematu syntaktycznego, według którego zostały połączone, by określić znaczenie całości."

Bei E. Łabno-Falęcka [15, S. 259] werden als Phraseologismen Sprachbilder genannt, die

„das Wesen komplizierter Erscheinungen in kurzer und prägnanter Form wiedergeben, gleichzeitig aber wegen ihrer nationalen Gebundenheit oft „unübersetzbar" sind, d. h. keine (phraseologischen) Äquivalente in anderen Sprachen aufweisen".

Als Beispiel nennt die Autorin Phraseologismen, die für eine bestimmte Sprache „typisch" sind:

Typisch deutsch

bei jmdm. ist Hopfen und Malz verloren - ,bei jmdm. ist alle Mühe umsonst,

jmd. ändert sich trotz aller Ermahnungen nicht mehr' [7, S. 349]

jmdn. über den grünen Klee loben - ,jmdm., etwas über Gebühr, übermäßig

Ioben' [7, S. 387]

frech wie Oskar - 'sehr frech' [7, S. 217]

Dagegen als typisch polnisch gelten $u$. a.:

spiec raka - 'zaczerwienić się' (erröten)

wyjść na czymś jak Zabłocki na mydle - 'ubić zły interes' (ein äußerst schlechtes Geschäft abschließen)

głupi Jasiu - 'głuptas' (Dummkopf)

Der Unterschied zwischen Phraseologismen und freien Wortverbindungen liegt in der fehlenden Reproduzierbarkeit der phraseologischen Einheiten, sodass sie nicht immer als generierungsoffene Schemata anzusehen sind. Sie bilden eine semantische Einheit und werden deshalb wie ein Lexem behandelt. Die Hauptmerkmale der Phraseologismen, die sie von anderen festen Wendungen unterscheiden, sind u. a. ihre Polylexikalität (formale Komplexität), Figuriertheit (nichtsummative Gesamtbedeutung), Festigkeit, Stabilität (auch: Fixiertheit). Die genannten Termini werden noch im Nachstehenden behandelt.

Derselben Herkunft wie der ,Phraseologismus' ist auch der Begriff ,Phraseologie'. Man unterscheidet zwei Auffassungen von Phraseologie, je nachdem welches der Kriterien angenommen wird. Aus diesem Grund unterscheidet man zwischen der Phraseologie im engeren und der Phraseologie im weiteren Sinne. Die erstere beschränkt ihr Forschungsobjekt auf feste Wortverbindungen mit dem idiomatischen Charakter (hoher Grad der Idiomatizität), deren Bedeutung nicht mehr aus den einzelnen Komponenten zu erschließen ist: 
etwas auf seine [eigene]Kappe nehmen (ugs.) - ,die Verantwortung für etwas übernehmen' [7, S. 371]

eine/die Mücke machen (ugs.) - ,sich davonmachen, verschwinden' [7, S. 494]

Derartige Phraseologismen müssen aus mehr als einem Wort bestehen und eine stabile syntaktische Struktur haben. Das entscheidende definitorische Merkmal der Phraseologismen ist bei dieser Einteilung ihre Idiomatizität. Demzufolge wird eine Wortverbindung erst dann als ,Phraseologismus im engeren Sinne' oder ,Idiom' bezeichnet, wenn eine ihrer Komponenten ihre freie, wendungsexterne Bedeutung verloren hat. (Nicht alle Phraseologieforscher z. B. R. Hessky, G. Kammer, sehen einen Sinn darin, einer Gruppe der Phraseologismen eine andere Bezeichnung zu geben. Das Problem hat darüber hinaus auch einen regionalen Charakter.)

Von der ,Phraseologie im weiteren Sinne' ist dann die Rede, wenn man als Hauptmerkmal der Phraseologismen ihre Festigkeit betrachtet. Diese Bezeichnung wird auf folgende Weise erklärt: „Sie werden nicht frei nach den Regeln der jeweiligen Einzelsprache produziert, sondern liegen bereits als Rede (Diskurs) anwendungsbereit vor und werden abgerufen, wiederholt'. [15, S. 143].

Endgültig hat sich in der deutschen Phraseologie die weitere Auffassung der Phraseologie durchgesetzt, d. h. die Phraseologie im weiteren Sinne. Demzufolge werden als Phraseologismen (auch: Paralexeme, Wortgruppenlexeme, feste/phraseologische Wendungen, phraseologische Einheiten) solche Einheiten des Wortschatzes betrachtet, die bereits vorgeformt sind und daher wie ein Lexem in der Kommunikation gebraucht werden. Die Komponenten eines Phraseologismus sind syntaktisch verbunden und lexikalisch bzw. semantisch modifiziert - der Sprecher empfindet sie als ein Lexem. Eine Minimalstruktur der phraseologischen Einheit besteht aus einem Autosemantikon (Lexem der Hauptwortart mit Eigenbedeutung) und einem Synsemantikon (Lexem mit grammatischer Funktion), [16, S. 83]. Sie sind feste Wortverbindungen (aber - bis auf wenige Ausnahmenkeine Satzkonstruktionen) und müssen zu einem Satz ergänzt werden [2, S. 16]. Phraseologismen haben oft ein zugrunde liegendes Bild, was aber nicht immer ihre übertragene Bedeutung voraussetzt. Dieses Merkmal wird als ,Bildhaftigkeit' bezeichnet. Man spricht in Bezug auf die Struktur des Phraseologismus von der Festigkeit, die dermaßen erstarrt ist, dass der Austausch der Komponenten zur Bildung einer freien Wortgruppe führen kann. Die Festigkeit äußert sich nicht nur in der beschränkten Austauschbarkeit. In den meisten Fällen verhalten sich 
Phraseologismen syntaktisch nicht mehr wie freie Syntagmen, weil sie eine feste Wortstellung haben (hinten und vorne, mit Ach und Krach, Ebbe und Flut versus polnisch przypływy i odpływy) oder nicht konjugiert sind.

Im Nachstehenden wird die Vielfalt der phraseologischen Erscheinungen dargestellt.

\section{Klassifikationsmöglichkeiten der phraseologischen Wortverbindungen}

Es gibt mehrere Konzeptionen der Gliederung von Phraseologismen, je nachdem, welches Kriterium man wählt. Jeder Sprachforscher nimmt zum Zweck seiner Fragestellung andere Kriterien vor.

In der polnischen Phraseologie werden die Phraseologismen nach dem formalen und semantischen Kriterium geteilt. Im Falle des formalen Kriteriums handelt es sich um grammatische Merkmale und nach diesem Kriterium wird für lexikographische Zwecke verfahren. Demnach werden die festen Wortverbindungen von S. Skorupka [23, S. 9] in drei Gruppen geteilt:

1. Wyrażenia (nominale, adverbiale und adjektivische Gefüge)

z. B.: prawa ręka (jmds. rechte Hand)- 'najbliższy współpracownik'

(,jmds. Vertrauter und wichtigster Mitarbeiter'; [7, S. 298]

Das sind Verbindungen von mindestens zwei Wörtern, die eine syntaktische Einheit bilden und einen nominalen Charakter haben. Das Zentrum der Wendung bildet in der Regel ein Substantiv oder ein Adjektiv, manchmal ein Partizip oder Adverb. Dazu werden von Skorupka auch festgeprägte präpositionale, adverbiale Verbindungen gezählt: fala morska, kraina mlekiem i miodem płynąca etc.

2. Zwroty (verbale Phraseologismen mit einem verbalen Kern)

z. B. być przeciw (gegen etwas sein) - ,opowiadać się przeciwko czemuś'

Zu dieser Gruppe gehören syntaktisch verbundene Wörter mit der verbalen

Basis: pleść trzy po trzy (albernes Zeug reden), prawdę mówiąc (ehrlich gesagt) etc.

3. Frazy (nominal-verbale, pädikative Einheiten)

z. B. iść komuś na rękę (jmdm. an die Hand gehen) - ,uwzględnić czyjeś życzenia, interesy' (jmdn. bei der Arbeit unterstützen)

Wortverbindungen dieser Gruppe bestehen aus nominalen und verbalen Komponenten und können als ein Satz in der Kommunikation vorkommen. Dabei kann es sich um einen einfachen oder zusammengesetzten Satz handeln. 
S. Skorupka [23, S. 6] weist aber auch auf die Relation Phrase-Satz hin, dass man die Phrase nicht mit einem Satz verwechseln soll. Zu der Phraseologie werden nur diese Sätze gezählt, die mehr oder weniger in der Sprache geprägt sind, die oft in der gleichen Form wiederholt werden und in gleicher Reihenfolge. Es sind unterschiedliche Redewendungen, Sentenzen, Maximen, Aphorismen und Sprichwörter.

Nach dem semantischen Kriterium werden die Wortverbindungen geteilt in:

1. stałe (idiomatische Phraseologismen)

Mindestens eine Komponente der Wortverbindung muss wendungsinterne Bedeutung haben. Lexeme bilden lexikalische Einheiten, die wie ein Lexem in der Kommunikation gebraucht werden, d. h. sie können mit einem Wort ersetzt werden oder mit einem synonymen Phraseologismus. Ihre Gesamtbedeutung ist nicht gleich der Summe ihrer Kompnenten, z. B. stary grzyb (wörtliche Bedeutung: ,ein alter Pilz'; phraseologische Bedeutungsvariante:

,ein alter Mann'), dwa grzyby w barszcz (wörtlich: ,zwei Pilze in den Borschtsch'; Phraseologische Bedeutung: ,etwas Überflüssiges'), [23, S. 7].

2. łączliwe (teilidiomatische Phraseologismen)

Die Komponenten solcher Wortverbindung haben ihre freie Bedeutung bewahrt aber als Ganzes bilden sie eine fixierte Form, z. B. dobry/ różowy/ świetny/ zły humor (gute Laune). Die Grenze zwischen festen und verbindungsfähigen Wortverbindungen ist flüssig. An der Peripherie dieser Gruppe liegen Funktionsvergefüge, z. B. wykonać skok (skoczyć), wyciągnąć wniosek (wnioskować) usw. und feste Vergleiche, die einen stereotypen Charakter haben, aber ihre Gesamtsumme der Summe ihrer Komponenten gleicht: blady jak kreda (blass wie Kreide), biały jak śnieg (weiß wie der Schnee); ciężki jak słoń (schwer wie ein Elephant); podobni do siebie jak dwie krople wody (sie ähneln einander wie ein Ei dem anderen) [23, S. 7].

3. luźne (freie Wortverbindungen)

Das sind Wortverbindungen, die immer neu und okkasionell gebildet werden, weil sie eine einfache Verbindung der freien Lexeme sind: droga przez wieś (der Weg durch das Dorf), droga przez las (der Weg durch den Wald), etc. das einzige gemeinsame Element ist das Lexem droga (der Weg), [23, S. 7].

Dieser Typ von Wendungen ist in den phraseologischen Wörterbüchern nicht vorzufinden.

Als anderes Beispiel der Gliederung wird jetzt die von $\mathrm{H}$. Burger dargestellt, die nach dem der Metaphorik naheliegenden Kriterium der Motiviertheit erfolgt. Nach seiner Basisklassifikation unterscheidet man 
je nach ihrer Zeichenfunktion drei Gruppen von Phraseologismen: Referentielle, kommunikative und strukturelle phraseologische Einheiten.

Als Grundprinzip eines Phraseologismus betrachtet Burger ihre besondere Art semantischer und syntaktischer Regularitäten der Verknüpfung und ihre Lexikalisierung. Er unterscheidet zwischen

(1) phraseologischen Wortverbindungen und

(2) idiomatisch-phraseologischen Wortverbindungen.

Die erstgenannte Gruppe gehört bei Fleischer zu der Peripherie des phraseologischen Untersuchung.

Innerhalb der zweiten Gruppe werden die Phraseologismen wegen des Grades der Idiomatizität in zwei Gruppen weiter geteilt in:

* Idiome im engeren Sinne

* Idiome im weiteren Sinne

Bei Idiomen im engeren Sinne ist die Bedeutung der Redensart aus den Bedeutungen den Komponenten nicht erschließbar, weil ihre Bedeutungen innerhalb der Wendung semantische Modifikation erfahren haben. Sie sind demzufolge unmotiviert. Abgeschwächte Motiviertheit, die nachvollziehbar ist, kennzeichnet Idiome im weiteren Sinne. Das Kriterium für die idiomatisch- phraseologische Wortverbindungen ist also die Nachvollziehbarkeit der übertragenen Bedeutung. Das Phänomen der Idiome, der "irreguläirsten Phraseologismen" [4, S. 19], wird im zweiten Teil dieser Arbeit detalliert dargestellt, deshalb wurde in diesem Punkt nur ein Überblick verschafft. Auch die an der Peripherie der Phraseologie liegende feste Wendungen wurden hier in aller Kürze dargestellt.

In dem Modell von Christine Palm [18] werden Phraseologismen nach den Kriterien der Festigkeit und Stabilität, ferner auch der Idiomatizität in folgende zwei Gruppen geteilt:

a) Phraseologismen im engeren Sinne (Phraseme)

b) Phraseologismen im weiteren Sinne

Phraseme (auch: ,Idiome', ,Redensarten', ,Wortgruppenlexeme', 'Phraseolexeme') können satzwertig sein und ihre syntaktische Struktur ist unterschiedlich. Die Bedeutung der Komponenten ist mehr oder weniger modifiziert, wenn ihre Verknüpfung irregulär ist. Die reguläre Verknüpfung hat zur Folge, dass die wendungsexterne Bedeutungsvariante der Komponenten erhalten bleibt. $\mathrm{Zu}$ den Phraseologismen im weiteren Sinne gehören in dieser Klassifikation:

- Sprichwörter und Antispritiwörter

- Sagwörter oder Wellerismen

- Lehnsprichwörter

- geflügelte Worte 
Morphologisches Paradigma und die Wortart der Komponenten sowie die potentielle Satzgliedrolle sind Kriterien der morpho- syntaktischen Klassifikation. Dies ist die bevorzugte Gliederung, die am häufigsten die Anwendung findet, weil man die Wortverbindung leicht im Lexikon auffinden kann, indem man nach dem Kernwort recherchiert. Es ergeben sich dabei folgende Gruppen von festen Wortverbindungen: substantivische Phraseologismen, verbale Phraseologismen, adjektivische Phraseologismen, adverbiale Phraseologismen, Phraseologismen mit Pronominaladverbien da-, Phraseologismen mit Numeralia, pronominale Phraseologismen.

Eine andere Möglichkeit der Klassifikation, die oft zitiert wird, ist ein Zentrum-Perpherie-Modell von W. Fleischer [10]. Zum Zentrum der Phraseologismen (laut diesem Modell) gehören Wortverbindungen, die ein Autosemantikon besitzen und sich durch die Merkmale der Idiomatizität, der Stabilität und der Lexikalisierung kennzeichnen. Wenn eines dieser Kriterien fehlt, dann wird die Wortverbindung in die Peripherie gerückt [10, S. 71]. Es sind im Prinzip die Hauptmerkmale der Phraseologismen und sie entscheiden darüber, ob die gegebene Wortgruppe dem Kernbereich (Zentrum) oder der Peripherie zugeordnet wird. In die Richtung Peripherie rücken kommunikative Formeln, die einen Textanschluss ermöglichen. Sie weisen entweder einen geringen oder gar keinen Grad der Idiomatizität auf.

Zwischen der Phraseologie und Syntax stehen Phraseoschablonen. Diese Gruppe umfasst unterschiedliche Konstruktionen. Das sind, mit Fleischer [10, S. 136] gesprochen, syntaktische Strukturen mit der variablen lexikalischen Füllung. Ihre Idiomatizität ist syntaktischer Art. Diese Konstruktionen haben eine irreguläre Bedeutung. Die meisten Phraseoschablonen haben die Bedeutung der Intensivierung, die mit unterschiedlichen Modellen ausgedrückt wird [10, S. 3]:

- sicher ist sicher, hin ist hin

- der Brief kommt und kommt nicht, der Wagen will und will nicht anspringen

- Schritt für Schritt, Schlag auf Schlag

- Buch der Bücher, Spiel der Spiele

Phraseoschablonen können auch expressive Wertung zum Ausdruck bringen:

- dieses Bierfass von einem Kerl

- es ist zum Heulen/Verrücktwerden/. . .

- du hast gut lachen/reden/. . .

Eine besondere Gruppe von Phraseoschablonen bilden Funktionsverbgefüge, die nur eine grammatische Funktion erfüllen. Wortgruppe der Art ist eine 
"Verbindung aus einem inhaltsarmen Verb und einem sinntragenden Substantiv" [6, S. 767].

Das sind Streckformen des Verbs. In der Verbindung deverbatives Substantiv + Verb hat das Verb (Funktionsverb v. a. bringen, kommen, geben, machen) eine verblasste modifizierende Bedeutung, die sich von der wendungsexternen Bedeutung unterscheidet:

treffen - freie Bedeutung: ,begegnen'

Entscheidung treffen - ,sich entscheiden'

Die Wahl treffen - ,wählen'

zum Ausdruck bringen - ,ausdrücken'

Entscheidung treffen - ,sich entscheiden'

Die Hauptsinnträger sind Akkusativobjekt bzw. Präpositionalgruppe, die samt dem Verb das Prädikat bilden. Daraus folgt, dass man dieses Gefüge oft durch ein Vollverb ersetzen kann. Es muss aber mit dem Hauptsinnträger etymologisch verwandt sein.

Jetzt zum Zentrum dieses Modells. Feste Wendungen, die wegen ihrer Merkmale als Phraseologismen bezeichnet werden, sind teil- oder vollidiomatische Einheiten, sog. Phraseolexeme. Sie erfüllen die Kriterien der Idiomatizität und Stabilität, und sie sind durch die Tendenz zur Speicherung im Lexikon gekennzeichnet. Diese werden weiter in nominale, verbale, adjektivische und adverbiale Phraseologismen untergliedert.

Die angeführten Beispiele der Definitionen zeigen, dass in dem deutschen und in dem polnischen Sprachsystem auf die gleichen Merkmale phraseologischer Wendungen hingedeutet wird.

\subsection{Sprichwörter und Antisprichwörter}

Da Idiome auch als, sprichwörtliche Redensarten' bezeichnet werden, könnte man vermuten, dass sie in die Nähe der Sprichwörter gehören. Das ist aber eine falsche Vermutung, weil sie sich in Form, Funktion und Struktur voneinander unterscheiden. 'Paremia nie są jednak jednostkami leksykalnymi, lecz minimalnymi tekstami, utrwalonymi społecznie. Podlegają weryfikacji logicznej, warunki ich użycia są określone pragmatycznie a nie gramatycznie" [17, S. 12]. Diese Abgrenzung ist aber nicht immer problemlos [21, S. 10]: "Die Grenzen zwischen Sprichwort und sprichwörtlicher Redensart werden in dem Augenblick fließend, wo Sprichwörter bzw. Redensarten in einen dichterischen Text eingeflochten werden." Am kürzesten könnte man diese Art von festen Wortverbindungen mit Worten von A. Sabban [22, S. 44] charakterisieren:

"Sprichwörter sind (soweit sie die Form eines Aussagesatzes haben) Allsätze mit Anspruch auf allgemeine Gültigkeit". 
Wir wollen noch andere Definition zitieren, die die wichtigsten Merkmale der Sprichwörter berücksichtigt. Diese stammt von $\mathrm{H}$. Beyer [2, S. 6]:

"Sprichwörter sind allgemein oder zumindest weithin bekannte, fest und dauerhaft geprägte Sätze, die eine prägnant formulierte Lebensregel bzw. verallgemeinerte Lebenserfahrung enthalten. In ihrer komplexen Aussage und ausgefeilten Gestalt bilden sie zugleich Miniaturtexte von manchmal großem poetischem Reiz. Prägnanz und Volkstümlichkeit nach Inhalt und Form sind unerlässliche Voraussetzungen für die Geläufigkeit des Sprichworts und für eine weitgehend mündliche, oft über die Jahrhunderte reichende Überlieferung".

Strukturell gesehen sind sie also vollständige oder elliptische Sätze. Es fehlt bei innen ein Element, das auf die Sprechsituation verweisen würde. Die syntaktische Struktur der Sprichwörter bevorzugt Autosemantika. Sie haben feste Struktur und eine doppeldeutige Bedeutung, die nicht additiv aus den Bedeutungen seiner Komponenten erschließbar ist:

Wer $A$ sagt, muss auch $B$ sagen - wer etwas beginnt, muss es fortsetzen [und auch angenehme Folgen auf sich nehmen]' [7, S. 19]

Der Krug geht so lange zum Brunnen/Wasser, bis er bricht - ,übles Handeln

bleibt auf die Dauer nicht ungestraft; fragwürdiges Tun scheitert eines Tages' [7, S. 421]

Dagegen sprichwörtliche Redensarten sind verbale, bildhafte Ausdrücke, wo sich Zeit und Person ändern. Sprichwörter urteilen bewertend und in einer vereinfachenden oder generalisierenden Weise werden positive oder negative Eigenschaften zu- bzw. abgesprochen. Sie werden nicht wie Phraseologismen reproduziert sondern in Bezug auf eine Situation zitiert. Ein zusätzliches Merkmal, das übrigens auch für die sprichwörtliche Redensarten zutrifft, ist ihre vielfach ausgeprägte Bildlichkeit [21, S. 10], z. B.:

Die Ratten verlassen das sinkende Schiff; die Wände haben Ohren, Ausnahmen bestätigen die Regel, doppelt gibt, wer schnell gibt, jeder ist seines Glückes Schmied etc.

Die Form des Sprichworts wird oft durch Rhythmus, Stabreim, Endoder Binnenreim gefestigt [20, S. 251]. Wenn es sich um ihre Relation zu den Phraseologismen handelt, dann stehen die beiden Gruppen von Wortverbindungen oft in einer Wechselbeziehung zueinander, weil Sprichwörter durch syntaktische Prozesse zu sprichwörtlichen Redensarten werden können. Das kann zum Beispiel durch Hinzufügen oder Reduktion eines Elements zustande kommen: 
Sprichwort: Stille Wasser sind tief - ,äußerlich zurückhaltende, ruhige Menschen

haben oft überraschende [Charakter] Eigenschaften' [7, S. 782]

Idiom: stilles Wasser

Das Sprichwort, das in einer originalen oder eingedeutschten Variante geläufig ist, bezeichnet man als Lehnsprichwort. Die Quelle der Lehnsprichwörter ist die Antike oder die Bibel, z. B. .:

gutta cavat lapidem Steter Tropfen höhlt den Stein

manus manum lavat Eine Hand wäscht die andere

Manchmal werden Sprichwörter ironisch als sog. Antisprichwörter gebraucht. Das ironische Effekt wird durch den Austausch einer der Komponenten verursacht. [18, S. 5]:

Sprichwort: Viele/alle Wege führen nach Rom - es gibt mehrere Möglichkeiten, ein Ziel zu erreichen' [7, S. 786]

Antisprichwort: Ausnahmen bestätigen die Regel, sagte der Weg und führte an Rom vorbei

Sprichwort: Was lange währt, wird endlich gut - geduldiges Warten, geduldiges Sichbemühen wird am Ende belohnt' [7, S. 431]

Antisprichwort: Was lange gärt, wird endlich Wut

Man soll neben dem Sprichwort auch Gemeinplätze nennen, denn sie beide werden als sog. topische Formeln (oder Topoi) bezeichnet nach dem Begriff "Topos" aus der antiken Rhetorik.

Gemeinplätze formulieren nur Selbstverständlichkeiten, Binsenweisheiten:

Was man hat, das hat man

Sie werden gebraucht, wenn etwas unumgänglich bewertet wird zum Zweck der Bewertung oder Rechtfertigung einer Handlung.

In der polnischen Phraseologieforschung werden die festen Wortverbindungen dieser Gruppe (przysłowia) als Wendungen definiert, die durch Bild und Allegorie einen Gedanken mitteilen. Typisch für sie ist der didaktische Charakter. Ihre Quelle ist entweder das Volkstradition oder die Literatur [19, S. 740].

Zu den Sprichwörtern werden auch einige Maximen und Sentenzen gezählt:

Mit dieser Gruppe der phraseologischen Wortverbindungen befasste sich v.a.J. Krzyżanowski [23]. Er definierte diese Wendungen als literarische Miniaturformen mit Reim und Rhythmus, deren Form mehr oder weniger stabil ist. Als feste Kombinationen werden sie in der Kommunikation reproduziert. Der Autor nennt folgende Sprichwort-Merkmale:

1. Stabile Form - sie werden in einer unveränderlichen Form gebraucht, keine der Komponenten wird erweitert, reduziert oder ersetzt. 
Es werden auch keine Leerstellen eröffnet, die man mit einem Objekt füllen könnte.

Baba z wozu, koniom lżej

*Monika z wozu, koniom lżej.

In diesem Beispiel hat die Wendung ihre übertragene Bedeutung verloren und kann sich nur auf eine konkrete außersprachliche Situation beziehen.

2. Allegorie - bildhafte Darstellung eines abstrakten Begriffes mittels z. B. symbolischer Handlungen etc.: "Darstellung eines abstrakten Begriffs durch ein (personifizierendes) rational fassbares Bild" [5, S. 91].

"wyrażenie w mowie, piśmie i sztuce prawd i uogólnień o ludzkim postępowaniu i doświadczeniu za pomocą symbolicznych, fikcyjnych postaci, działań, a także całej fabuły (zwłaszcza bajek, przypowieści); obrazowe przedstawienie pojęć oderwanych, głównie za pomocą personifikacji" [13, S. 24].

Zum Beispiel.:

Kruk krokowi oka nie wykole

Jeśli wejdziesz między wrony musisz krakać jak i one.

3. Bildhaftigkeit - Sprichwörter sprechen mit Bildern:

Lody zostały przełamane

Kot z domu - myszy po stole tańcują

Bliższa koszula ciału niż sukmana

4. Lehrhafte Tendenz, die sich z. B. als Warnung äußern kann:

Nosił wilk razy kilka, ponieśli i wilka

Kto pod kim dołki kopie, często sam w nie wpada

Heutzutage werden Sprichwörter nicht nur als goldene Lebensregel verstanden. Man gebraucht sie spielerisch, um der Aussage einen besonderen stilistischen Ausdruck zu verleihen - es kann ein Spott oder eine Ironie sein. Aus diesem Grund werden sie mit Vorliebe in der Presse, Werbung u. ä. zitiert:

„Sprichwörter sind so lebendig wie eh und je, mag auch ihre Funktion anders, ihre Zahl geringer sein als vor Jahrhunderten. [...]. Sie sind nicht mehr schlechthin unentbehrliche Medien bei der Vermittlung sozialer Erfahrung und Moral von einer Generation zur anderen. [...]. Das Prägnante und das Formelhafte des Sprichworts geben ihm nach wie vor eine eindringliche, suggestive Kraft, die im Alltag wie von Presse, Werbung und bei vielen anderen Gelegenheiten ausgiebig genutzt wird. Sprichwörtliches ,kommt an'" [2, S. 5].

H. Beyer [2, S. 14] weist darauf hin, dass man gegenwärtig als Sprichwörter eine Mischung von Sprichwörtern und geflügelten Worten empfindet. 


\subsection{Sagwörter oder Wellerismen}

Sagwörter sind eine Sondergruppe der Sprichwörter, die von jemandem zitiert werden und in eine Situation gestellt, wohin sie überhaupt nicht passen. Der Begriff, Wellerismus' geht auf die Figur aus Dickens' „Pickwick Papers" - Samuel Weller. Der Terminus wurde von Archer Taylor eingeführt.

Wegen inrer Variabilität ist diese Gruppe der festen Wortverbindungen nach wie vor produktiv [2, S. 14]. Die Besonderheit dieser Wendungen äußert sich in dem Sagte-Teil, in dem man erfährt, wer die sprechende Person ist. Das Verb ,sagen' erscheint dabei immer in der Präteritum-Form. Wellerismen bestehen meistens aus drei Teilen:

Was sich liebt, das neckt sich, sagte die Katze und fraß die Maus

Alter schützt vor Torheit nicht, sagte die Greisin, und ließ sich liften

Seltener kommen sie in einer zweigliedrigen Form vor:

Haben, haben, sagte der Hund.

oder als Dialog:

Der Mann ist die Krone der Schöpfung, sagte der Mann und ich bin das Kreuzchen darauf, sagte die Frau.

Wellerismen - im Gegensatz zu den Sprichwörtern - keine ethischen Werte vermitteln. Sie dienen allein einer Provokation. Sie sind keinesfalls als ernsthafte Lebensregeln zu verstehen. Ihr Ziel ist es, die menschlichen Laster mit Ironie, Spott oder Witz darzustellen.

Sagwörter entstehen auch gegenwärtig und werden v. a. im Niederdeutschen bevorzugt gebraucht, z. B.:

Zeit ist Geld, sagte der Ober und addierte das Datum mit [2, S. 15]

Das ist Geschmack[s]sache, sagte der Affe und biss in die Seife [7, S. 30]

Im Polnischen werden diese Wortverbindungen als powiedzenie bezeichnet, als eine kurze Äußerung typisch für eine Person, die von anderen gern wiederholt wird:

„zwięzła, zwykle aforystyczna wypowiedź, często właściwa komuś, chętnie powtarzana przez kogoś" [9, S. 829]

\subsection{Geflügelte Worte}

W. Fleischer [10, S. 20] definiert geflügeltes Wort als

"ein landläufiges Zitat, d. h. [...] ein in weiteren Kreisen des Vaterlandes dauernd angeführter Ausspruch, Ausdruck oder Name, gleichviel welcher Sprache, dessen historischer Urheber, oder dessen literarischer Ursprung nachweisbar ist", z. B.:

Grau, teurer Freund, ist alle Theorie. (Goethe)

Vom Winde verweht. (Margaret Mitchell)

Erst kommt das Fressen, dann kommt die Moral. (Brecht) 
Die Bezeichnung dieser Gruppe der festen Wortverbindungen ist auf Georg Büchmanns Sammlung (erschien erstmalig 1864) zurückzuführen, wo er diesen Terminus gebraucht und definiert hat [2, S. 16].

Geflügelte Worte zitiert man in vergleichbarer Situation. Ihr typisches Merkmal ist ihre Quelle, die nachweisbar ist. Sie können aber zu den Phraseologismen werden. Die Phraseologisierung vollzieht sich durch verschiedene syntaktische oder lexikalische Umformungen unter der Bedingung, dass die Quelle nicht mehr nachvollziehbar ist. Dieser Prozess ist möglich, weil dieser Typ der festen Wendungen nicht an die Satzstruktur gebunden ist [10, S. 84].

\subsection{Sentenz, Maxime, Aphorismus}

Maxime ist als eine allgemeine Lebensregel zu verstehen. Ähnlich wie ein geflügeltes Wort ist sie autorenbezogen. Sentenz wird durch lehrhafte Tendenz gekennzeichnet sowie durch ihren Ursprung in einem künstlerischen Werk. Das ist ein kurzer, einprägsamer Ausspruch in Satzform mit einer Lebenserkenntnis, in der Regel aber mehr philosophisch betrachtender Art. Ein Oberbegriff für die Sentenz ist das geflügelte Wort.

Aphorismus ist wie geflügeltes Wort autorenbezogen und bildet eine Art Gegenpol zum Sprichwort. Das sind originelle, geistreiche Gedankensplitter, die bestimmte Verhaltensweisen und Erkenntnisse in Frage stellen [2, S. 17]. Die Quelle dieser Wendungen ist die Antike und es waren zuerst Ratschläge oder Erkenntnisse. Ihre Blüte erlebten sie in der Renaissance. Zu festen Wendungen dieser Art gehören zum Beispiel:

"Die Vernunft formt den Menschen, das Gefühl leitet ihn" JeanJacques Rousseau

"Der Aberglaube ist die Poesie des Lebens, deswegen schadet dem Dichter nicht, abergläubisch zu sein" Goethe

"Gäbe es nicht Gott, so müsste man ihn erfinden" Voltaire

"Sie steinigten ihn mit einem Denkmal" Stanisław Jerzy Lec

"Alle Männer sind ichbezogene Kinder" Christa Wolf

Diese Wortverbindungen sind auch die Quelle der Phraseologismen, jedoch eine weniger produktive als z. B. Sprichwörter [15, S. 198]. Den Aphorismen sind Maximen eng verwandt.

In der polnischen Sprache definiert man feste Wortverbindungen dieser Gruppe als:

złota myśl - „zdanie, sąd celnie wyrażające jakąś cenną myśl, prawdę ogólną, jakieś ogólne przesłanie; sentencja, maksyma,; w liczbie mnogiej wybór takich maksym, powiedzeń" [9, S. 1364).

aforyzm - „krótkie, zwięzłe powiedzenie wyrażające jakąś ogólną myśl filozoficzną, moralną, życiową itp., zwykle ujęte w błyskotliwej 
formie; sentencja, maksyma". [9, S. 4] maksyma (sentencja) - „ogólna prawda, prawidło, zasada podstawowa, reguła postępowania, zwłaszcza wyrażone w formie aforyzmu, krótkiej sentencji". [13, S. 315].

\subsection{Vergleichsformeln}

Diese Wortverbindungen sind, wie Zwillingsformeln, einfache Formen und Strukturen. Die Abgrenzung der Vergleichsformeln von den Phraseologischen Wortverbindungen bereitet erhebliche Schwierigkeiten. Der Grund dafür ist eine nicht mehr verständliche Komponente, die sie manchmal enthalten. Man könnte dabei von einer unikalen Komponente sprechen, weil sie nur diachronisch zu motivieren ist:

dumm wie Bohnenstroh

Innerhalb dieser Gruppe gibt es auch sog. stereotype Vergleiche:

weiß wie Schnee/ Kreide

Bis auf wenige Ausnahmen (schnell wie der Blitz) werden sie in den Themenbereich der Phraseologie nicht aufgenommen - wegen ihrer starken Veränderbarkeit. Sie werden v. a. scherzhaft und ironisch gebraucht.

In dem polnischen Sprachsystem existieren auch diese Formen, für die die genannten Merkmale zutreffen.

z. B.: Głupi jak but z lewej nogi, spać jak suseł, pasować jak pięść do nosa etc.

\subsection{Zwillingsformeln (auch: Wortpaare)}

"Sie sind die einfachsten formalen Redensartenschemata" [21, S. 12]. Diese starren phraseologischen Wortverbindungen sind durch Stabreim oder Endreim gebunden. Eine unveränderbare Reihenfolge ihrer Komponenten wird durch den Rhythmus bewirkt. Das ist ein Typ der festen Wortverbindungen, in dem es sich um Verstärkung des Sachverhaltes handelt, den sie zum Ausdruck bringen. Man unterscheidet dabei zwischen zwei Gruppen:

(a) Hand in Hand; wenn schon, denn schon; Auge um Auge, Zahn um Zahn

(b) Haut und Knochen; von A bis Z; Hals über Kopf

Die erste Gruppe (a) bilden solche Formeln, die durch Wiederholung des gleichen Lexems gebildet werden zum Zweck der Verstärkung. In der Gruppe (b) werden die Zwillingsformeln aus verschiedenen Wörtern zusammengesetzt. Sie werden so gebildet, dass das kürzere Wort dem längeren vorangestellt wird. Auch steht das Wichtigere voran (Sonne und Mond). Es ist dabei hervorzuheben, dass sie feststehende Wortfolge haben.

\subsection{Pragmatische Phraseologismen}

Es sind Konstruktionen, die für Kommunikationspartner eindeutig sind, d. h. sie haben nur eine wörtliche Bedeutung und so zu verstehen sind. Sie 
sind im gewissen Sinne fest, weil man sie immer im bestimmten Kontext, in der gleichen außersprachlichen Situation gebraucht, z. B. Guten Appetit! beim Essen, oder Toi,toi toi! als Glückwunsch. Pragmatische Phraseologismen haben keine stilistische Funktion und sind primär eine Art der Signale.

Die kurz angeschnittenen Formen zeichnen sich durch usuelle Geltung, Reproduzierbarkeit, syntaktische und semantische Stabilität und oft Idiomatizität. Diese Merkmale heben sie zwar von freien Wortverbindungen $a b$, aber sie gehören nur in den Bereich der Phraseologie-Peripherie. Daraus folgt, dass sie nicht so oft wie andere Gruppen der Phraseologismen, die das Zentrum der Phraseologie bilden, behandelt werden [15, S. 165].

Die dargestellten Möglichketen der Einteilung der Phraseologismen auch wenn nur in der Form einer Übersicht- macht uns der Vielfalt derartigen Wortverbindungen bewusst. Die kontrastive Sicht lässt die Deutsch Lernenden viele- nicht nur stilistische Fehler vermeiden und vielleicht auch die Phraseologie der Muttersprache neu entdecken.

\section{Literaturverzeichnis}

1. Bąba Stanisław/Liberek Jarosław. Słownik frazeologiczny współczesnej polszczyzny. Wydawnictwo naukowe PWN. Warszawa, 2002

2. Beyer Horst und Annelies (1985). Sprichwörterlexikon. Sprichwörter und sprichwörtliche Ausdrücke aus deutschen Sammlungen vom 16. Jahrhundert bis zur Gegenwart. Verlag C. H. Beck. München.

3. Burger Harald, Buhofer Annelies und Sialm Ambros. Handbuch der Phraseologie. Walter de Gruyter. Berlin, 1982.

4. Dobrovol'skij Dmitrij. Kognitive Aspekte der Idiom-Semantik. Studien zum Thesaurus deutscher Idiome. Gunter Narr Verlag. Tübingen, 1995.

5. Duden, Deutsches Universal Wörterbuch A-Z. Mannheim, 1996.

6. Duden, Band 4. Die Grammatik. Mannheim, 1984.

7. Duden, Band 11. Redewendungen und sprichwörtliche Redensarten. Mannheim, 1998.

8. Duden, Band 12 Zitate und Aussprüche, Mannheim, 1998.

9. Dunaj Bogusław. Słownik współczesnego języka polskiego. Warszawa, 1996.

10. Fleischer Wolfgang. Phraseologie der deutschen Gegenwartssprache. Leipzig,1982.

11. Fleischer Wolfgang. Phraseologie der deutschen Gegenwartssprache. 2. durchgesehene und ergänzte Auflage. Max Niemeyer Verlag. Tübingen, 1997.

12. Keil Martina (1997). Wort für Wort. Repräsentation und Verarbeitung verbaler Phraseologismen (Phraseo-Lex). Max Niemeyer Verlag. Tübingen, 1997.

13. Kopaliński Władysław. Słownik wyrazów obcych $i$ zwrotów obcojęzycznych. Wiedza Powszechna, 1989.

14. Krzyżanowski Julian. Nowa księga przysłów wyrażeń przysłowiowych polskich. Warszawa, 1969. 
15. Łabno-Falęcka Ewa. Phraseologie und Übersetzen: eine Untersuchung der Übersetzbarkeit kreativ-innovativ gebrauchter wiederholter Rede anhand von Beispielen aus der polnischen und deutschen Gegenwartsliteratur. Peter Lang GmbH Europäischer Verlag der Wissenschaften. Frankfurt am Main, 1995.

16. Mitrache Liliana. Intertextualität und Phraseologie in den drei Versionen der „Panne" von Fredrich Dürrenmatt. Aspekte von Groteske und Ironie. Uppsala Universität. Stockholm, 1999.

17. Pajdzinska Anna (1993). Frazeologizmy jako tworzywo wspótczesnej poezji. Agencja Wydawniczo-Handlowa. Lublin, 1993.

18. Palm Christine. Phraseologie. Eine Einführung. Gunter Narr Verlag. Tübingen, 1995.

19. PWN . Słownik wyrazów obcych. Warszawa, 1980.

20. Rudi Conrad. Kleines Wörterbuch sprachwissenschaftlicher Termini. VEB Bibliographisches Institut. Leipzig, 1975.

21. Röhrich Lutz. Lexikon der sprichwörtlichen Redensarten, Bd. 1. Verlag Herder GmbH \& Co. KG. Freiburg im Breisgau, 1973.

22. Sabban Annette. Okkasionelle Variationen sprachlicher Schematismen. Eine Analyse französischer und deutscher Presse- und Werbetexte. Gunter Narr Verlag. Tübingen, 1998.

23. Skorupka Stanisław. Słownik frazeologiczny języka polskiego. Wiedza Powszechna. Warszawa,1968.

\section{References}

1. Bąba Stanisław/Liberek Jarosław. (2002). Słownik frazeologiczny współczesnej polszczyzny. Wydawnictwo naukowe PWN. Warszawa.

2. Beyer Horst und Annelies (1985). Sprichwörterlexikon. Sprichwörter und sprichwörtliche Ausdrücke aus deutschen Sammlungen vom 16. Jahrhundert bis zur Gegenwart. Verlag C. H. Beck. München.

3. Burger Harald, (1982). Buhofer Annelies und Sialm Ambros. Handbuch der Phraseologie. Walter de Gruyter. Berlin.

4. Dobrovol'skij Dmitrij (1995) Kognitive Aspekte der Idiom-Semantik. Studien zum Thesaurus deutscher Idiome. Gunter Narr Verlag. Tübingen.

5. Duden, (1996). Deutsches Universal Wörterbuch A-Z, Mannheim,

6. Duden, (1984). Band 4. Die Grammatik. Mannheim.

7. Duden, (1998). Band 11. Redewendungen und sprichwörtliche Redensarten. Mannheim.

8. Duden, (1998). Band 12 Zitate und Aussprüche, Mannheim.

9. Dunaj Bogusław (1996). Słownik współczesnego języka polskiego. Warszawa.

10. Fleischer Wolfgang (1982). Phraseologie der deutschen Gegenwartssprache. Leipzig.

11. Fleischer Wolfgang (1997). Phraseologie der deutschen Gegenwartssprache. 2. durchgesehene und ergänzte Auflage. Max Niemeyer Verlag. Tübingen.

12. Keil Martina (1997). Wort für Wort. Repräsentation und Verarbeitung verbaler Phraseologismen (Phraseo-Lex). Max Niemeyer Verlag. Tübingen. 
13. Kopaliński Władysław (1989). Słownik wyrazów obcych i zwrotów obcojęzycznych. Wiedza Powszechna, 1989.

14. Krzyżanowski Julian (1969). Nowa księga przysłów wyrażeń przysłowiowych polskich. Warszawa.

15. Łabno-Falęcka Ewa (1995). Phraseologie und Übersetzen: eine Untersuchung der Übersetzbarkeit kreativ-innovativ gebrauchter wiederholter Rede anhand von Beispielen aus der polnischen und deutschen Gegenwartsliteratur. Peter Lang GmbH Europäischer Verlag der Wissenschaften. Frankfurt am Main.

16. Mitrache Liliana. Intertextualität und Phraseologie in den drei Versionen der "Panne" von Fredrich Dürrenmatt. Aspekte von Groteske und Ironie. Uppsala Universität. Stockholm, 1999.

17. Pajdzinska Anna (1993). Frazeologizmy jako tworzywo współczesnej poezji. Agencja Wydawniczo-Handlowa. Lublin.

18. Palm Christine (1995). Phraseologie. Eine Einführung. Gunter Narr Verlag. Tübingen.

19. PWN. (1980). Słownik wyrazów obcych. Warszawa,

20. Rudi Conrad (1975). Kleines Wörterbuch sprachwissenschaftlicher Termini. VEB Bibliographisches Institut. Leipzig,

21. Röhrich Lutz. (1973). Lexikon der sprichwörtlichen Redensarten, Bd. 1. Verlag Herder $\mathrm{GmbH} \&$ Co. KG. Freiburg im Breisgau,.

22. Sabban Annette. (1998). Okkasionelle Variationen sprachlicher Schematismen. Eine Analyse französischer und deutscher Presse- und Werbetexte. Gunter Narr Verlag. Tübingen.

23. Skorupka Stanisław. (1968). Słownik frazeologiczny języka polskiego. Wiedza Powszechna. Warszawa

\author{
Маріуш Мілчарек \\ ад'юнкт (доцент) кафедри іноземних мов \\ Гуманітарно-економічної академії (Лодзь, Польща) \\ спеціальність "Мовознавство"
}

\title{
Класифрікація фразеологічних сполучень: німецько-польський контрастний погляд
}

У статті акцентовано на словосполученнях, які (завдяки своїй фріксованій формі і специфрічному значенню) несуть додаткове емоційне забарвлення. Знання фразеологізмів важливе для вивчення іноземної мови і роботи перекладача. При правильному використанні вони збагачують висловлювання і свідчать про високий рівень володіння іноземною мовою. Натомість їх неналежне використання може призвести до незапланованого комічного ефекту або навіть до порушення зв'язку. У статmі (на основі різних вихідних текстів) представлено критерії, за якими визначаються фрразеологізми в німецькій і польській мовах. Представлено різноманіття таких груп слів в обох мовах.

Ключові слова: фрразеологія, фразеологізми, загальні фррази, прислів'я. 